\title{
Reactive orange 16 dye adsorption from aqueous solutions by psyllium seed powder as a low-cost biosorbent: kinetic and equilibrium studies
}

\author{
Mohammad Malakootian $^{1,2} \cdot$ Mohammad Reza Heidari $^{3}$
}

Received: 18 April 2018 / Accepted: 11 October 2018 / Published online: 28 October 2018

(c) The Author(s) 2018

\begin{abstract}
The biosorption process using natural materials has found widespread applications than to their inexpensiveness, availability, and reusability. The aim of this research is to investigate the efficiency of psyllium seed powder in removal of reactive orange 16 dye. The impacts of various influential parameters such as initial $\mathrm{pH}$, contact time, adsorbent dose, temperature and dye concentration were evaluated using a batch biosorption method. Data analysis was conducted by SPSS 19 . The removal efficiency of reactive dye 16 using the natural adsorbent psyllium was obtained to be $94 \%$ in optimal conditions (pH 4, contact time $=40 \mathrm{~min}$, and adsorbent dose $=2 \mathrm{~g} / \mathrm{L}$ ). Biosorption equilibrium experiments indicated that the best fit was achieved with Langmuir isotherm model. Maximum adsorption capacity was found to be $206.6 \mathrm{mg} / \mathrm{g}$ at $303 \mathrm{~K}$. Kinetic analysis revealed that adsorption experimental data were best fitted by pseudo-second-order model. Free energy of adsorption $\left(\Delta G^{\circ}\right)$, enthalpy $\left(\Delta H^{\circ}\right)$, and entropy $\left(\Delta S^{\circ}\right)$ changes were calculated to predict the nature of adsorption. Thermodynamic evaluation indicates that a spontaneous process has occurred. Inexpensive, locally available, and effective materials could be used for dye removal in wastewater treatment processes. Undoubtedly low-cost adsorbent benefits for commercial purposes in the future.
\end{abstract}

Keywords Psyllium $\cdot$ Biosorbent $\cdot$ Reactive dye $\cdot$ Isotherm $\cdot$ Kinetic $\cdot$ Thermodynamic

\section{Introduction}

The extent of production of dye in the world is estimated to be 1 million tons/year; synthetic dyes are widely use in industries including cosmetics, leather, paper, and textile industries (Ahmadian et al. 2012; Rahimi et al. 2016; Samadi et al. 2015). Textile industries are one of the largest consumers of dyes with different chemical quantities and qualities (Geetha et al. 2015; Qi et al. 2017). Textile dyes

Mohammad Malakootian

m.malakootian@yahoo.com

Mohammad Reza Heidari

moheidari86@gmail.com

1 Environmental Health Engineering Research Center, Kerman University of Medical Sciences, Kerman, Iran

2 Department of Environmental Health, School of Public Health, Kerman University of Medical Sciences, Kerman, Iran

3 Department of Environmental Health, School of Public Health, Bam University of Medical Sciences, Bam, Iran are the largest group of water-soluble synthetic dyes, having the greatest variety in terms of dye type and structure (Malakootian et al. 2015a, b). Dyes can be categorized into different types that are usually classified based on their particle charge upon dissolution in aqueous application medium such as cationic (all basic dyes), anionic (direct, acid, and reactive dyes), and non-ionic (Yagub et al. 2014). Dyes have a complex molecular structure which is mostly carcinogenic, mutagenic, unbiodegradable, and stable, causing harmful effects to the environment (Zhang et al. 2015). Discharge of dye wastewaters resulting from textile industries to water body results in reduced sunlight penetration and unfavorable sight situation, reducing photosynthesis and increasing turbidity of water (Zadeh and Malakootian 2017). Further, by decreasing the intensity of photosynthesis of water plants and algae in aquatic environment, they cause environmental damage, as a result of which effective and efficient treatment of them is an environmental necessity (Ponnusami et al. 2008; Yu et al. 2009). Reactive orange 16 dye is known as a reactive dye, which has one atom or a set of susceptible atoms which react with cellulose hydroxyl or amino acid functional group of wool and eventually with similar 
synthetic fabric (Shen and Gondal 2017; Wang et al. 2015, 2017).

Types of treatment used for dye removal are coagulation (Kuppusamy et al. 2017), chemical oxidation (Malakootian et al. 2015a, b; Samarghandi et al. 2014), ozonation (Ghuge and Saroha 2018), reverse osmosis (Wang et al. 2018), membrane filtration, and electrochemical (Malakootian et al. 2017). Adsorption process is one of the most effective processes of advanced wastewater treatment, with low cost, availability, and reusability being its major advantages over other methods (Asgari et al. 2014; Moussavi et al. 2013, 2014; Seid-Mohammadi et al. 2014; Malakootian et al. 2018). The use of natural adsorbents is a simple, fast, and practical method due to being free from problems associated with separation, filtration, etc. (Malakootian et al. 2018). Various low-cost materials have been studied as potential biosorbents for dye adsorption such as green composite (Deniz and Ersanli 2016), chitosan (Chen et al. 2017), cactus fruit peel (Kumari et al. 2017), chitin/lignin (Wawrzkiewicz et al. 2017), alginate nanoparticles (Geetha et al. 2015), tannery solid waste (Mella et al. 2017), Penicillium janthinellum (Wang et al. 2015), Haloxylon recurvum (Hassan et al. 2017).

Psyllium is the common name used for several members of the plant genus Plantago (Singh et al. 2007). Seeds of Plantago commercially referred to as psyllium. The dried, ripe seeds of Plantago such as psyllium, arenaria, and ovata are used in medicine and pharmacology. The mucilage obtained from the seed coat by mechanical milling/grinding of the outer layer of the seeds contains arabinose, xylose, and non-reducing terminal residues. Mucilage is a white fibrous hydrophilic material and forms the clear colorless mucilaginous gel by absorbing water and water uptake in oil/water emulsion for use in oil refineries (Rao et al. 2016; Singh et al. 2007). Plantago has advantages such as chemically inert, non-toxic, low cost, biodegradable and widely available. In this study, the bioremoval of reactive dye was investigated by psyllium seed powder. The effects of important operating variables like $\mathrm{pH}$, contact time, adsorbent dose, temperature and initial dye concentration on the adsorption of reactive dye were investigated through bath biosorption experiments. Scanning electron microscope and transmission electron microscopy were used for the characterization of the biosorbent. The isotherms (Langmuir, Freundlich), kinetics (Pseudo-first-order, pseudo-second-order, and intraparticle diffusion models), and thermodynamic studies were performed.

\section{Materials and methods}

\section{Biosorbent preparation}

The psyllium was crushed by manual mill and sifted by an 18-30 mesh sieve so that the size of the adsorbent would reach $0.5 \mathrm{~mm}$. Scanning electron microscope (SEM) device and transmission electron microscopy (TEM) are used to observe the physical structure of the adsorbents surface in Fig. 1.

To remove debris and soil, they were washed with deionized water and dried at $50{ }^{\circ} \mathrm{C}$ for $24 \mathrm{~h}$. Up to the application, the adsorbent was kept in a desiccator or plastic bottle. Thereafter, the adsorbent was dried in steel container at $50{ }^{\circ} \mathrm{C}$ for $24 \mathrm{~h}$. Then, to conduct the thermochemical reaction, the oven temperature was adjusted at $120{ }^{\circ} \mathrm{C}$ for $90 \mathrm{~min}$. Once the adsorbent was cooled down, it was washed with distilled water at neutral $\mathrm{pH}$ and then filtered. The kinetic models, pseudo-first-order, pseudo-second-order, and intraparticle diffusion model have been used for this study (Li et al. 2010).

\section{Biosorbate preparation}

The chemical structure of dye shown in Fig. 2 was purchased from Sigma-Aldrich. To prepare the stock solution of concentration $1000 \mathrm{mg} / \mathrm{L}, 1000 \mathrm{mg}$ of dye powder was mixed with $1 \mathrm{~L}$ of distilled water in a volumetric flask. It was then diluted with distilled water accordingly to obtain working solutions of the desired concentrations. Measurement of dye concentration in the experimental samples was done by
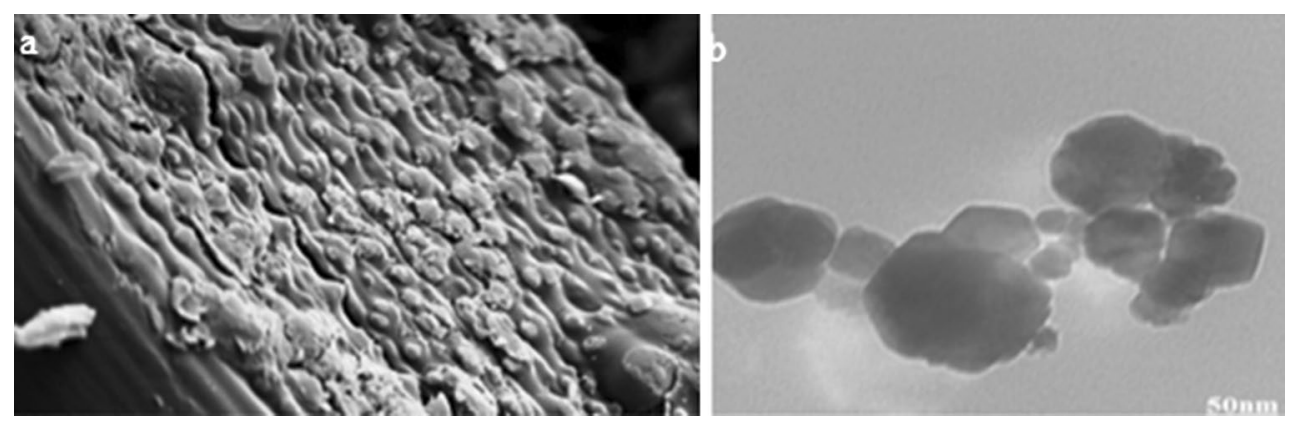

Fig. 1 SEM (a) and TEM (b) of the molecular structure of the biosorbent

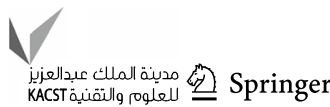


<smiles>COS(=O)(=O)OCCS(=O)(=O)c1ccc(N=Nc2c(S(=O)(=O)O[Na])cc3ccc(NC(C)=O)cc3c2O)cc1</smiles>

Fig. 2 Chemical structures reactive organic 16

UV-Vis spectrophotometer (HACH-USA) at the wavelength of $492 \mathrm{~nm}$ (Marrakchi et al. 2017).

\section{Batch biosorption studies}

To do the experiments, Jar test device was used. A certain amount of the psyllium adsorbent was added to each beaker. First, the fast mixing stage was done at $200 \mathrm{rpm}$ for $2 \mathrm{~min}$. Then, for each slow mixing stage, rate of $40 \mathrm{rpm}$ was considered for $15 \mathrm{~min}$ with sedimentation time of $30 \mathrm{~min}$. After each jar test, samples were immediately taken from the sampling solution from a depth of $4 \mathrm{~cm}$ below the surface (Ai and Jiang 2010). Across all of the stages of the experiment, the same dye concentrations but without adsorbent were used as control samples. To optimize the adsorption conditions, the optimal values of each of the factors influencing the biosorption process: $\mathrm{pH}(2-10)$, contact time (5-300 $\mathrm{min})$, biosorbent dose $(0.5-2 \mathrm{~g} / \mathrm{L})$, initial dye dose $(50-300 \mathrm{mg} / \mathrm{L})$, and temperature $\left(283-303^{\circ} \mathrm{K}\right)$ were studied. $\mathrm{HCl}$ and $\mathrm{NaOH} 0.1 \mathrm{~mol} / \mathrm{L}$ were employed to adjust the $\mathrm{pH}$ of the samples. The adsorption experiments were replicated three times at each stage. Analysis of variance was then performed to retain the significant terms $(p<0.05)$ and exclude the insignificant terms $(p>0.05)$ (Deniz and Ersanli 2016).

The amount of dye biosorbed per gram of psyllium is calculated using Eq. (1):

$q_{\mathrm{e}}=\frac{\left(C_{0}-C_{\mathrm{e}}\right) V}{W}$

The percent dye biosorbed from aqueous solution by psyllium is calculated using Eq. (2):

Percent dye biosorbed $=\left[1-\frac{C_{\mathrm{e}}}{C_{0}}\right] \times 100$

where $C_{0}(\mathrm{mg} / \mathrm{L})$ is the initial concentration, $C_{\mathrm{e}}(\mathrm{mg} / \mathrm{L})$ equilibrium concentration, $V$ is the volume of dye solution (L), and $W$ is the mass $(\mathrm{g})$ of the adsorbent.

\section{Biosorption isotherms and kinetics}

Adsorption properties and equilibrium data, generally known as adsorption isotherms, describe how pollutant interacts
Table 1 The kinetic and isotherm models used for biosorption process on psyllium

\begin{tabular}{lll}
\hline Model & Parameters & Linear equation \\
\hline Kinetic & & \\
Pseudo-first order (Lagergren) & $q_{\mathrm{e}, \text { exp }}, k_{1}$ & $q_{\mathrm{e}}=q_{\mathrm{e}}\left(1-\mathrm{e}^{-k_{1} t}\right)$ \\
Pseudo-second order (Ho) & $q_{\mathrm{e}, \mathrm{exp}}, k_{2}$ & $\frac{t}{q_{t}}=\frac{1}{k_{2} q_{\mathrm{e}}^{2}}+\frac{1}{q_{\mathrm{e}}} t$ \\
$\begin{array}{l}\text { Intraparticle diffusion (Web- } \\
\text { ber) }\end{array}$ & $k_{\mathrm{i}}, C_{\mathrm{i}}$ & $q_{t}=k_{\mathrm{i}} t^{1 / 2}+C_{\mathrm{i}}$ \\
$\begin{array}{ll}\text { Isotherm } \\
\text { Freundlich }\end{array}$ & \\
Langmuir & $k_{\mathrm{F}}, n$ & $\ln q_{\mathrm{e}}=\ln k_{\mathrm{F}}+\frac{1}{n}\left(\ln C_{\mathrm{e}}\right)$ \\
\hline & $k_{\mathrm{L}}, q_{0}$ & $\frac{C_{\mathrm{e}}}{q_{\mathrm{e}}}=\frac{C_{\mathrm{e}}}{q_{0}}+\frac{1}{k_{\mathrm{L}} q_{0}}$ \\
\hline
\end{tabular}

with adsorbent materials and so they are critical in optimizing the use of adsorbent (Cotillas et al. 2014). The linear equations related to the mentioned kinetic models are presented in Table 1.

The pseudo-first-order model is based on solid capacity. This model considers the rate of occupation of biosorption sites proportional to the number of unoccupied sites. This model equation is shown in Table 1 where $k_{1}\left(\mathrm{~min}^{-1}\right)$ and $q_{\mathrm{e}}$ and $q_{t}(\mathrm{mg} / \mathrm{g})$ are rate constant, the biosorption capacity at a time $t$, and the equilibrium of pseudo-first-order kinetics. The pseudo-second-order model is associated with situation when the rate biosorption process controls the overall biosorption kinetics as shown in Table 1 where $k_{2}[\mathrm{~g} /(\mathrm{mg} / \mathrm{min})]$ is the second-order rate constant of adsorption. The initial sorption rate $[h(\mathrm{~g} / \mathrm{mg} \mathrm{min})]$ can be calculated by $h=k_{2} q_{\mathrm{e}}^{2}$. In the intraparticle diffusion model, $k_{\mathrm{i}}\left(\mathrm{mg} / \mathrm{g} \mathrm{min}^{0.5}\right)$ is the rate constant and $C_{\mathrm{i}}(\mathrm{mg} / \mathrm{g})$ provides insight into the boundary layer effect which increases proportionally with the intercept value (Hall et al. 1966; Langmuir 1918; Wang et al. 2015; Wawrzkiewicz et al. 2017).

Linear increase of Langmuir isotherm in Table 1 where $k_{\mathrm{L}}$ $(\mathrm{L} / \mathrm{mg})$ is the Langmuir constant and $q_{0}(\mathrm{mg} / \mathrm{g})$ is the maximum adsorption capacity; $C_{\mathrm{e}}(\mathrm{mg} / \mathrm{L})$ is the equilibrium concentration of dye in solution. Linear increase of Freundlich isotherm in Table 1 where $k_{\mathrm{F}}\left(\mathrm{mg}^{1-(1 / n)} \mathrm{L}^{1 / n} / \mathrm{g}\right)$ is the capacity of the adsorbent and $\mathrm{n}$ is the intensity of adsorption constant. The plot of $\ln q_{\mathrm{e}}$ versus $\ln C_{\mathrm{e}}$ is employed to determine the $k_{\mathrm{F}}$ and $n$ from intercept and slope, respectively (Konicki et al. 2017).

The thermodynamic parameters of the biosorption such as Gibbs free energy change, $\Delta G(\mathrm{~kJ} / \mathrm{mol})$, enthalpy change, $\Delta H$ $(\mathrm{kJ} / \mathrm{mol})$, and entropy change, $\Delta S(\mathrm{~kJ} / \mathrm{mol} \mathrm{K})$, are evaluated by Eqs. (3) and (4) (Tang et al. 2012).

$\Delta G^{0}=-R T \ln K_{\mathrm{L}}$

$\ln K_{\mathrm{L}}=\frac{\Delta S^{0}}{R}-\frac{\Delta H^{0}}{R T}$ 
In Eqs. 3 and 4, $R$ is the universal gas constant $(=8.314 \mathrm{~J} /$ $\mathrm{mol} \mathrm{K})$ and $k_{\mathrm{L}}(\mathrm{L} / \mathrm{mol})$ is the equilibrium constant. The values of $\Delta H^{\circ}$ and $\Delta S^{\circ}$ are calculated by plotting the linear diagram of $\ln k_{\mathrm{L}}$ versus $1 / T$, which are the slope and intercept of the linear equation of the mentioned diagram (Hassan et al. 2017). The fitting of experimental data to the isotherm and kinetic models was assessed by the correlation coefficient $\left(R_{2}\right)$ and the residual root mean square error (RMSE). The value of $R_{2}$ which may vary between 0 and 1 indicates the degree of fitting of experimental data to the model. The $R_{2}$ expression is given by Eq. (5):

$R_{2}=\frac{\sum_{i=1}^{N}\left(q_{\mathrm{e}}-q_{\mathrm{e}, \mathrm{exp}}\right)^{2}}{\sum_{i=1}^{N}\left(q_{\mathrm{e}}-q_{\mathrm{e}, \exp }\right)^{2}+\left(q_{\mathrm{e}}-q_{\mathrm{e}, \exp }\right)^{2}}$

The RMSE represents the match between the experimental data and the calculated data used for plotting the isotherm and kinetic models where $n$ is the number of data points. It is defined as (Eq. 6):

$\operatorname{RSME}=\sqrt{\frac{1}{n-2} \sum_{i=1}^{N}\left(q_{\mathrm{e}}-q_{\mathrm{e}, \mathrm{exp}}\right)^{2}}$

\section{Results and discussion}

\section{The effect of $\mathrm{pH}$}

The most important factors affecting the capacity of adsorbent are solution $\mathrm{pH}$. The efficiency of adsorption is dependent on the solution $\mathrm{pH}$, since variation in $\mathrm{pH}$ leads to the variation in the degree of ionization of the adsorptive molecule and the surface properties of adsorbent (Tang et al. 2012). Figure 3 reports the effect of solution $\mathrm{pH}$ on dye adsorption.

The removal efficiency for the contaminant increased by elevation of $\mathrm{pH}$ from 2 to 4 , while it diminished at $\mathrm{pH}_{\mathrm{s}}$ above 4 . The maximum removal efficiency for the anionic dye has been related to $\mathrm{pH} 4$ as large as $94.2 \%$. Thus, the subsequent experiments of the biosorption process on dye were performed at $\mathrm{pH} 4$ as the optimal $\mathrm{pH}$. The removal

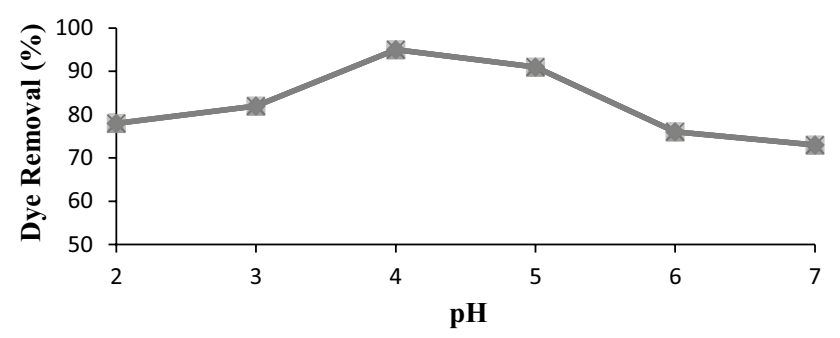

Fig. 3 The effect of changes in $\mathrm{pH}$ on the dye removal by biosorbent $\left(C_{0}=100 \mathrm{mg} / \mathrm{L}\right.$, time $=40 \mathrm{~min}$ and $\left.T=20^{\circ} \mathrm{C}\right)$ efficiency has had a descending trend at $\mathrm{pH}$ below 5. With the increase in $\mathrm{pH}$ from 5 to 10 , the removal efficiency has had a descending trend for the contaminant. This might be due to the tough competition between the extra $\mathrm{OH}^{-}$ions and the negatively charged molecules of the dye for adsorption on the surface of the adsorbent. The $\mathrm{pH}$ at which the surface charge is zero is called the point of zero charge (pzc) and is typically used to quantify or define the electrokinetic properties of a surface. The value of $\mathrm{pH}$ is used to describe pzc only for systems in which $\mathrm{H}^{+} / \mathrm{OH}^{-}$is the potential determining ions. Due to the presence of functional group such as $\mathrm{OH}^{-}$group, anionic dye adsorption is favoured at $\mathrm{pH}^{<} \mathrm{pH}_{\mathrm{pzc}}$ where the surface becomes positively charged (Liu et al. 2013). Similar results have been reported by natural polysaccharides-modified graphene oxide for anionic dye removal (Qi et al. 2017) and biosorption of dye by alginate nanoparticles (Geetha et al. 2015).

\section{Effect of contact time}

Contact times are the most important factors in the study of the adsorption process because they give data about the kinetic for complete interaction to the surface of the adsorbent (Greluk and Hubicki 2010). Figure 4 shows contact time for the dye adsorption examined over a 300-min period at initial concentrations of $50 \mathrm{mg} / \mathrm{L}$ of the contaminants at the optimal $\mathrm{pH}$.

The adsorption rate of the adsorbents has been far higher at initial times than subsequent times. In other words, with increase in contact time, the adsorption capacity increased for the contaminant. After $40 \mathrm{~min}$, virtually no significant change has occurred in the adsorption capacity. Thus, with increase in contact time from 40 to $300 \mathrm{~min}$, the adsorption capacity has increased from 22.5 to $23.7 \mathrm{mg} / \mathrm{g}$. This significant increase in the adsorption capacity at the beginning of contact time can be due to existence of numerous active and non-saturated sites in the external surfaces of

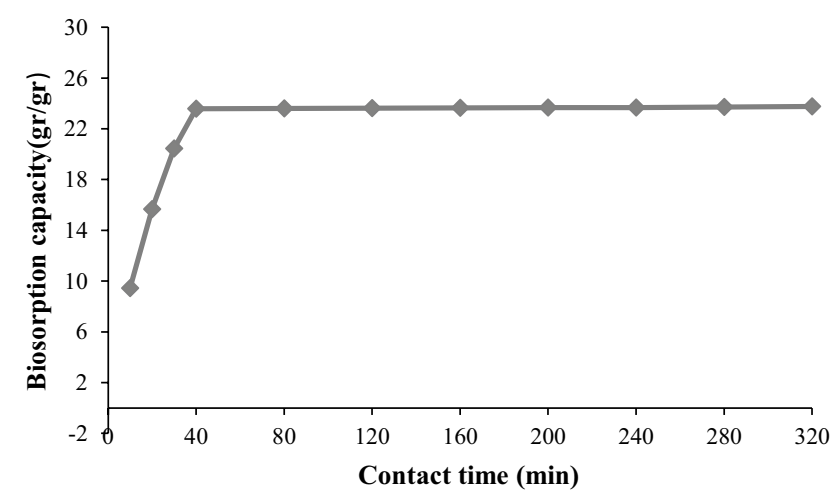

Fig. 4 The effect of changes in contact time on the dye removal by biosorbent $\left(T=20^{\circ} \mathrm{C}, \mathrm{pH} 4, C_{0}=100 \mathrm{mg} / \mathrm{L}\right)$ 
the adsorbent. However, over time, it is observed that the adsorption capacity has become stable for contaminant. This constancy of adsorption capacity, i.e., reaching the equilibrium point within duration longer than $60 \mathrm{~min}$ might be due to saturation of active sites on the surface of the adsorbent or completion of the adsorbent capacity (Satilmis and Budd 2017). Similar effects were observed by other researchers for contact time on the dye removal by different adsorbents (Kim et al. 2016; Konicki et al. 2017).

\section{Effect of amount of adsorbent}

Adsorbent dosage is a significant factor affecting process to determine the capacity of adsorbent for a given amount of the adsorbent. Figure 5 reports the results obtained from investigation of the effect of different concentrations of the adsorbent under the optimal conditions ( $\mathrm{pH} 4$ and contact time $=40 \mathrm{~min}$ ).

With the increase in the adsorbent dosage from 0.5 to $2 \mathrm{~g} / \mathrm{L}$, the percentage of dye removal from 70 to $94 \%$ but with the increase in the adsorbent dosage above $2 \mathrm{~g} / \mathrm{L}$ efficiency removal is fixed. Therefore, at $2 \mathrm{~g} / \mathrm{L}$, the removal efficiency has been above $90 \%$.

\section{Effect of initial dye concentration}

The effect of initial dye concentration depends on the active reaction between the concentration of the dye and the available pores on an adsorbent surface. Figure 6 indicates the results obtained from investigation of the effect of different dye concentrations under optimal conditions ( $\mathrm{pH} 4$ and contact time $=40 \mathrm{~min}$ ).

The variations in the initial dye concentration have had a negative impact on the extent of adsorption, such that with the increase in the initial concentration of the dye from 50 to $300 \mathrm{mg} / \mathrm{L}$, the removal efficiency grows from 90 to $94.3 \%$. Elevation of removal efficiency in investigation of changes in the amount of the adsorbed dye might be due to the saturation of adsorption sites on the adsorbent surface.

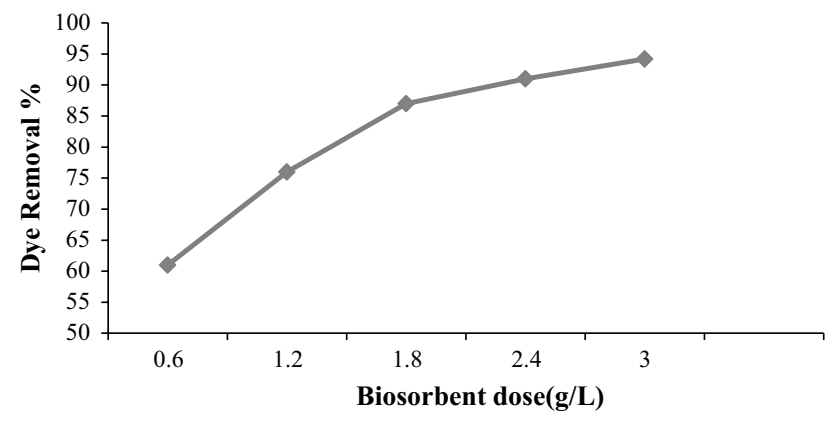

Fig. 5 The effect of changes in the biosorbent dosage on the dye removal $\left(T=20^{\circ} \mathrm{C}\right.$, time $\left.=40 \mathrm{~min}, \mathrm{pH} 4, C_{0}=100 \mathrm{mg} / \mathrm{L}\right)$

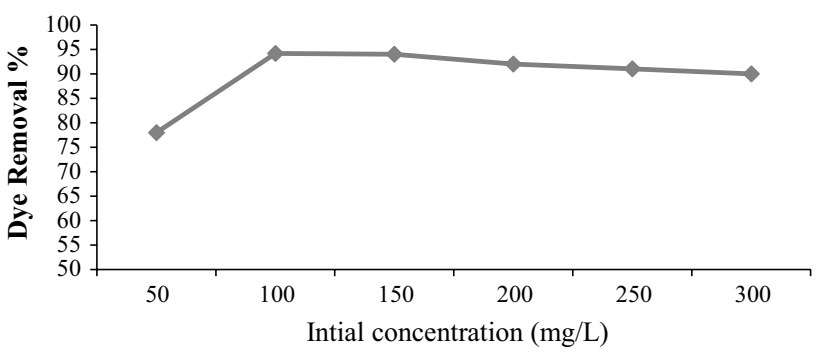

Fig. 6 The effect of changes in the concentration of the adsorbent on the dye removal efficiency by the biosorbent $\left(T=20^{\circ} \mathrm{C}\right.$, time $=40 \mathrm{~min}, \mathrm{pH} 4$ )

The constant of the number of active sites on the adsorbent versus the increase in the number of the molecules of the adsorbent or saturation of the adsorbent surface at high concentrations (Kim et al. 2016). The increase in dye concentration causes an increase in the driving force between the solution and biosorbent and hence the mass transfer resistance between the dye and the psyllium is reduced leading to an increase in the biosorption capacity (Kumari et al. 2017). Similar results are reported for the adsorption dye by biosorbent (Alizadeh et al. 2018).

\section{Adsorption kinetics}

The values of the kinetic parameters of the biosorption process of reactive 16 dye are presented in Table 2 for the initial concentration.

The values of calculated biosorption capacity $\left(q_{\mathrm{e}, \mathrm{cal}}\right)$ for the pseudo-first- and second-order kinetics were obtained as 22 and $24.2 \mathrm{mg} / \mathrm{g}$, respectively. Further, the experimental biosorption capacity $\left(q_{\mathrm{e}, \mathrm{exp}}\right)$ result is $23.5 \mathrm{mg} / \mathrm{g}$. The results indicate that the adsorption behavior of the contaminant over time follows pseudo-first-order and pseudo-second-order models, in accordance with the results of Rodrigo (Rodrigo et al. 2018). The higher values of $R_{2}$ for all the varying initial concentrations of dye indicate the better fit of pseudosecond-order kinetic model (Marrakchi et al. 2017). It is confirming that adsorption rate decreased with the increase in initial dye concentrations as observed by the effect of contact time study (Kumari et al. 2017). The kinetics of adsorption of many dye species onto various biosorbents was also found to be of pseudo-second-order in the literature: reactive orange 16 adsorption in carbonized fish scales (Marrakchi et al. 2017), reactive orange 16 on chitosan (Marrakchi et al. 2016), reactive orange 16 adsorption on brewery yeast (Kim et al. 2016).

The applicability of the pseudo-second-order model suggested that chemisorption might be the rate-limiting steps that control this adsorption process (Ahmad and Rahman 2011). Therefore, it can be concluded that the slowing stage in the dye biosorption process has been chemical biosorption (Masoomi

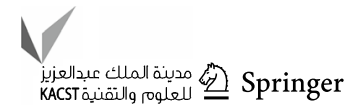


Table 2 Kinetic parameters of the biosorption process on psyllium

\begin{tabular}{|c|c|c|c|c|c|}
\hline $\begin{array}{l}\text { Adsorbent } \\
\text { Dye }\end{array}$ & Kinetic model & $\begin{array}{l}\text { Adsorbent } \\
\text { Dye }\end{array}$ & Kinetic model & $\begin{array}{l}\text { Adsorbent } \\
\text { Dye }\end{array}$ & Kinetic model \\
\hline Intraparticle diffusion & & Pseudo-second order & & Pseudo-first order & \\
\hline 0.5 & $k_{\mathrm{i}}$ & 24.2 & $q_{\mathrm{e}, \mathrm{cal}}(\mathrm{mg} / \mathrm{g})$ & 22 & $q_{\mathrm{e}, \mathrm{cal}}(\mathrm{mg} / \mathrm{g})$ \\
\hline 16.7 & $C_{\mathrm{i}}$ & 0.009 & $k_{1}\left(\min ^{-1}\right)$ & 0.07 & $k_{1}\left(\min ^{-1}\right)$ \\
\hline 0.6 & $R^{2}$ & 0.99 & $R^{2}$ & 0.98 & $R^{2}$ \\
\hline
\end{tabular}

Table 3 The parameters of equilibrium isotherms of biosorption process on psyllium

\begin{tabular}{|c|c|c|c|c|c|c|}
\hline \multirow{3}{*}{$\begin{array}{l}\text { Solution tempera- } \\
\text { ture }\left({ }^{\circ} \mathrm{K}\right)\end{array}$} & \multicolumn{6}{|c|}{ Equilibrium isotherms } \\
\hline & \multicolumn{3}{|c|}{ Freundlich } & \multicolumn{3}{|c|}{ Langmuir } \\
\hline & $R^{2}$ & $1 / n k_{\mathrm{F}}(\mathrm{mg} / \mathrm{g})$ & $(\mathrm{L} / \mathrm{mg})^{1 / n}$ & $\overline{R^{2}}$ & $k_{\mathrm{L}}(\mathrm{L} / \mathrm{mg})$ & $q_{0}(\mathrm{mg} / \mathrm{g})$ \\
\hline 283 & 0.98 & 0.69 & 9.45 & 0.99 & 0.03 & 201.1 \\
\hline 293 & 0.97 & 0.64 & 12.03 & 0.99 & 0.04 & 204.08 \\
\hline 303 & 0.97 & 0.62 & 13.23 & 0.99 & 0.04 & 206.6 \\
\hline
\end{tabular}

et al. 2017). The values related to the first $\left(k_{1}\right)$ - and second $\left(k_{2}\right)$-order reaction constant are almost the same, suggesting that reactive 16 dye molecules have been adsorbed on psyllium biosorbent with the same rate (Zuo et al. 2016). It is also observed that the value of boundary thickness layer $\left(C_{\mathrm{i}}\right)$ in the intraparticle diffusion model for the contaminant has not been zero. This suggests that intraparticle diffusion has not been the only controller stage of the process and possibly external adsorption mechanism has also been influential as a controlling factor in the biosorption process (Wawrzkiewicz et al. 2017).

\section{Biosorption isotherms}

Adsorption isotherms are essential for explaination of how biosorbate will interact with biosorbent and are critical for optimization, interpretation, and prediction of adsorption data (Deniz and Ersanli 2016). Thus, the equilibrium data were analyzed using Freundlich and Langmuir isotherm models. Table 3 indicates the values of the parameters of Langmuir and Freundlich equilibrium isotherms for adsorbed dye within $283-303{ }^{\circ} \mathrm{K}$.

The correlation regression coefficients $\left(R_{2}\right)$ revealed that the adsorption processes were better explained by Langmuir model ( $R_{2}=0.99$ for Langmuir and $R_{2}=0.97$ for Freundlich). The Langmuir isotherm fits with the experimental data that due to the homogeneous distribution of active sites onto the biosorbent surface (Kumari et al. 2017). The maximum biosorption capacity $\left(q_{0}\right)$ based on Langmuir model was obtained as $206.6 \mathrm{mg} / \mathrm{g}$ at $303{ }^{\circ} \mathrm{K}$. The separation factor, $R_{\mathrm{L}}$, can be determined from Langmuir plot as per the following Eq. (7):

$R_{\mathrm{L}}=\frac{1}{1+K_{\mathrm{L}} C_{0}}$

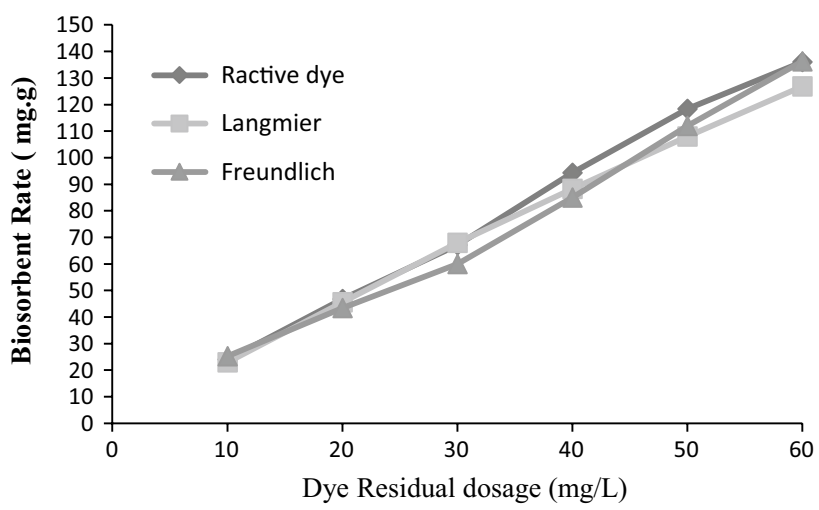

Fig. 7 The curve of the equilibrium models of biosorption process on the adsorbed dye $\left(T=20^{\circ} \mathrm{C}\right.$, time $\left.=40 \mathrm{~min}, \mathrm{pH} 4, C_{0}=100 \mathrm{mg} / \mathrm{L}\right)$

where $R_{\mathrm{L}}$ value in this study was favorable $\left(0<R_{\mathrm{L}}<1\right)$ (Greluk and Hubicki 2010). Figure 7 presents the comparison of the calculated equilibrium parameters according to the isotherm models for dye adsorption on psyllium.

As shown in Fig. 7, the maximum values of biosorption capacity have increased with the rise in the solution temperature, based on Langmuir isotherm model for the contaminant. For example, with the increase from 283 to $303{ }^{\circ} \mathrm{K}$, the maximum biosorption capacity for the dye has also grown from 201.1 to $206.6 \mathrm{mg} / \mathrm{g}$. Similar results in others studies are reported where malachite green dye removal by calcium Alginate (Geetha et al. 2015), brilliant green removal by binary oxidized cactus fruit peel (Kumari et al. 2017). This trend suggests that elevation of temperature has had a positive effect on the biosorption capacity (Faulconer et al. 2012); thus, it is concluded that biosorption of reactive 16 dye has been favorable 
Table 4 The thermodynamic parameters of the biosorption process on psyllium

\begin{tabular}{llll}
\hline $\begin{array}{l}\text { Solution tem- } \\
\text { perature }\left({ }^{\circ} \mathrm{K}\right)\end{array}$ & $\Delta G^{\circ}(\mathrm{kJ} / \mathrm{mol})$ & $\Delta H^{\circ}(\mathrm{kJ} / \mathrm{mol})$ & $\Delta S^{\circ}(\mathrm{kJ} / \mathrm{mol} \mathrm{K})$ \\
\hline 283 & -2.11 & 9.33 & 0.04 \\
293 & -2.43 & & \\
303 & -2.77 & & \\
\hline
\end{tabular}

on biosorbent (Greluk and Hubicki 2010). 1/n values related to Freundlich isotherm have been low for all of the three studied temperatures, which also suggests favorable biosorption of the contaminant on the adsorbed dye (Ahmad and Rahman 2011). Intensity of dye adsorption interactions was expressed by $n$ values (Wawrzkiewicz et al. 2017). The values of $n$ in the range of 1-10 represent good adsorption (Lawal et al. 2017). The result of this study was $1<n<10$, indicating favorable adsorption (Elwakeel 2009; Ramavandi and Farjadfard 2014).

\section{Thermodynamic study}

Thermodynamic study of the adsorption process is necessary to demonstrate the feasibility of the process. Table 4 also presents the values obtained for each of the thermodynamic parameters of the biosorption process.

The values of standard enthalpy $\left(\Delta H^{\circ}\right)$ have obtained positive value which indicated that the biosorption process is endothermic in nature; hence, biosorption is more favorable at higher temperatures. The enthalpy changes $\left(\Delta H^{\circ}\right)$ and entropy $\left(\Delta S^{\circ}\right)$ of adsorption were $9.33 \mathrm{~kJ} / \mathrm{mol}$ and $0.04 \mathrm{~J} / \mathrm{mol} \mathrm{K}$, respectively. The positive value for $\Delta H^{\circ}$ indicates that the adsorption of reactive dye onto psyllium is an endothermic process, where there is an increase in temperature in the solid-liquid interface along the biosorption process (Ramavandi and Farjadfard 2014). The positive value of entropy reflects the affinity of the adsorbent for reactive dye. The low value of $\Delta S^{\circ}$ may imply that no significant change in entropy occurred during the dye biosorption by psyllium (Liu et al. 2013). The estimated values of standard free energy $\left(\Delta G^{\circ}\right)$ for adsorption dye onto psyllium were $22.64,24.11$, and $26.35 \mathrm{~kJ} / \mathrm{mol}$, respectively, at 283,293 , and $303 \mathrm{~K}$. These results indicate that in all temperatures studied values of $\Delta G^{\circ}$ have been found to be negative which confirms feasibility and a spontaneous physiosorption process occurred. These negative values imply that the biosorption reaction of reactive 16 dye on psyllium biosorbent is spontaneous and possible (Ramavandi and Farjadfard 2014; Wang et al. 2017).

\section{Conclusion}

Psyllium showed efficiency for dye removal from aqueous solution. The optimal conditions for the adsorbent of reactive dye in this study are $\mathrm{pH} 4$, contact time $=40 \mathrm{~min}$, biosorbent dose $=2 \mathrm{~g} / \mathrm{L}$, and temperature $=303^{\circ} \mathrm{K}$. The maximum biosorption capacity was $206.6 \mathrm{mg} / \mathrm{g}$ and fitted very well to the Langmuir mode $\left(R_{2}=0.99\right)$. The kinetic of biosorption followed pseudo-second-order model. The removal efficiency of the contaminant increased with increase in the contact time, adsorbent dose, and the solution temperature. However, the initial concentration of the contaminant had an indirect effect on the biosorption efficiency. Due to its high specific surface area, psyllium is able to be used as an effective, efficient, and economical adsorbent in removing many environmental contaminants from water resources. The endothermic nature and spontaneity of the process were confirmed by thermodynamic studies. Thus, this biosorbent is expected to be widely used for fast and simple separation of a wide variety of adsorbed dyes from solutions. As main advantages for the use of psyllium are available, low cost, safe, easy operating conditions, high efficiency in decolonization, and no chemical requirements thus have been proposed to treat industrial wastewater containing organic pollutants and technically easier without large quantities of solutions. The maximum adsorption capacity of psyllium for reactive dyes was in comparison with other research. Since the variety of pollution removal using psyllium has not been studied, future studies must focus on the use of psyllium in more realistic conditions such as many different organic pollutants and the application in industrial wastewaters.

Acknowledgements This paper is carried out in the Environmental Health Engineering Research Center of Kerman University of Medical Sciences and was sponsored by the Vice-Chancellor for Research and Technology of Kerman University of Medical Sciences. The authors take this opportunity to express their gratitude for the support and assistance extended by the facilitators during the conduct of the research.

Open Access This article is distributed under the terms of the Creative Commons Attribution 4.0 International License (http://creativeco mmons.org/licenses/by/4.0/), which permits unrestricted use, distribution, and reproduction in any medium, provided you give appropriate credit to the original author(s) and the source, provide a link to the Creative Commons license, and indicate if changes were made.

\section{References}

Ahmad MA, Rahman NK (2011) Equilibrium, kinetics and thermodynamic of Remazol Brilliant Orange 3R dye adsorption on coffee husk-based activated carbon. Chem Eng J 170:154-161

Ahmadian M, Yosefi N, Toolabi A, Khanjani N, Rahimi S, Fatehizadeh A (2012) Adsorption of direct yellow 9 and acid orange

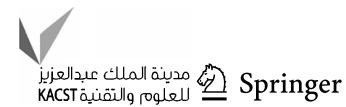


7 from aqueous solutions by modified pumice. Asian J Chem 24:3094

Ai L, Jiang J (2010) Fast removal of organic dyes from aqueous solutions by AC/ferrospinel composite. Desalination 262:134-140

Alizadeh B, Delnavaz M, Shakeri A (2018) Removal of Cd (II) and phenol using novel cross-linked magnetic EDTA/chitosan/TiO 2 nanocomposite. Carbohyd Polym 181:675-683

Asgari G, Seid Mohammadi A, Poormohammadi A, Ahmadian M (2014) Removal of cyanide from aqueous solution by adsorption onto bone charcoal. Fresenius Environ Bull 23:720-727

Chen A, Shang C, Shao J, Lin Y, Luo S, Zhang J, Huang H, Lei M, Zeng Q (2017) Carbon disulfide-modified magnetic ion-imprinted chitosan-Fe(III): a novel adsorbent for simultaneous removal of tetracycline and cadmium. Carbohyd Polym 155:19-27

Cotillas S, Llanos J, Miranda OG, Díaz-Trujillo GC, Cañizares P, Rodrigo MA (2014) Coupling UV irradiation and electrocoagulation for reclamation of urban wastewater. Electrochim Acta 140:396-403

Deniz F, Ersanli ET (2016) Simultaneous bioremoval of two unsafe dyes from aqueous solution using a novel green composite biosorbent. Microchem J 128:312-319

Elwakeel KZ (2009) Removal of reactive black 5 from aqueous solutions using magnetic chitosan resins. J Hazard Mater 167:383-392

Faulconer EK, Von Reitzenstein NVH, Mazyck DW (2012) Optimization of magnetic powdered activated carbon for aqueous $\mathrm{Hg}$ (II) removal and magnetic recovery. J Hazard Mater 199:9-14

Geetha P, Latha M, Koshy M (2015) Biosorption of malachite green dye from aqueous solution by calcium alginate nanoparticles: equilibrium study. J Mol Liq 212:723-730

Ghuge SP, Saroha AK (2018) Catalytic ozonation of dye industry effluent using mesoporous bimetallic $\mathrm{Ru}-\mathrm{Cu} / \mathrm{SBA}-15$ catalyst. Process Saf Environ Prot 118:125-132

Greluk M, Hubicki Z (2010) Kinetics, isotherm and thermodynamic studies of reactive black 5 removal by acid acrylic resins. Chem Eng J 162:919-926

Hall KR, Eagleton LC, Acrivos A, Vermeulen T (1966) Pore-and soliddiffusion kinetics in fixed-bed adsorption under constant-pattern conditions. Ind Eng Chem Fundam 5:212-223

Hassan W, Farooq U, Ahmad M, Athar M, Khan MA (2017) Potential biosorbent, Haloxylon recurvum plant stems, for the removal of methylene blue dye. Arab J Chem 10:S1512-S1522

Kim Y, Bae J, Park H, Suh J-K, You Y-W, Choi H (2016) Adsorption dynamics of methyl violet onto granulated mesoporous carbon: facile synthesis and adsorption kinetics. Water Res 101:187-194

Konicki W, Aleksandrzak M, Moszyński D, Mijowska E (2017) Adsorption of anionic azo-dyes from aqueous solutions onto graphene oxide: equilibrium, kinetic and thermodynamic studies. J Colloid Interface Sci 496:188-200

Kumari HJ, Krishnamoorthy P, Arumugam T, Radhakrishnan S, Vasudevan D (2017) An efficient removal of crystal violet dye from waste water by adsorption onto TLAC/Chitosan composite: a novel low cost adsorbent. Int J Biol Macromol 96:324-333

Kuppusamy S, Venkateswarlu K, Thavamani P, Lee YB, Naidu R, Megharaj M (2017) Quercus robur acorn peel as a novel coagulating adsorbent for cationic dye removal from aquatic ecosystems. Ecol Eng 101:3-8

Langmuir I (1918) The adsorption of gases on plane surfaces of glass, mica and platinum. J Am Chem Soc 40:1361-1403

Lawal IA, Chetty D, Akpotu SO, Moodley B (2017) Sorption of Congo red and reactive blue on biomass and activated carbon derived from biomass modified by ionic liquid. Environ Nanotechnol Monit Manag 8:83-91

Li P, Su Y-J, Wang Y, Liu B, Sun L-M (2010) Bioadsorption of methyl violet from aqueous solution onto Pu-erh tea powder. J Hazard Mater 179:43-48
Liu W, Yao C, Wang M, Ji J, Ying L, Fu C (2013) Kinetics and thermodynamics characteristics of cationic yellow X-GL adsorption on attapulgite/rice hull-based activated carbon nanocomposites. Environ Prog Sustain Energy 32:655-662

Malakootian M, Mansoorian HJ, Hosseini A, Khanjani N (2015a) Evaluating the efficacy of alumina/carbon nanotube hybrid adsorbents in removing Azo Reactive Red 198 and Blue 19 dyes from aqueous solutions. Process Saf Environ Prot 96:125-137

Malakootian M, Yousefi N, Fatehizadeh A, Van Ginkel SW, Ghorbani M, Rahimi S, Ahmadian M (2015b) Nickel (II) removal from industrial plating effluent by fenton process. Environ Eng Manag J 14:837-842

Malakootian M, Yazdanpanaha G, Poorjahanshahib M (2017) A comparison of the effectiveness of electrocoagulation to coagulation processes using ferric chloride for the removal of cadmium from aqueous solution. Desalin Water Treat 78:215-220

Malakootian M, Hashemi M, Toolabi A, Nasiri A (2018) Investigation of nickel removal using poly (amidoamine) generation 4 dendrimer (PAMAM G4) from aqueous solutions. J Eng Res 6:13-23

Marrakchi F, Khanday W, Asif M, Hameed B (2016) Cross-linked chitosan/sepiolite composite for the adsorption of methylene blue and reactive orange 16. Int J Biol Macromol 93:1231-1239

Marrakchi F, Ahmed MJ, Khanday W, Asif M, Hameed B (2017) Mesoporous carbonaceous material from fish scales as low-cost adsorbent for reactive orange 16 adsorption. J Taiwan Inst Chem Eng 71:47-54

Masoomi MY, Bagheri M, Morsali A (2017) Porosity and dye adsorption enhancement by ultrasonic synthesized Cd (II) based metalorganic framework. Ultrason Sonochem 37:244-250

Mella B, Puchana-Rosero M, Costa D, Gutterres M (2017) Utilization of tannery solid waste as an alternative biosorbent for acid dyes in wastewater treatment. J Mol Liq 242:137-145

Moussavi S, Ehrampoush M, Mahvi A, Ahmadian M, Rahimi S (2013) Adsorption of humic acid from aqueous solution on single-walled carbon nanotubes. Asian J Chem 25:5319

Moussavi S, Ehrampoush M, Mahvi A, Rahimi S, Ahmadian M (2014) Efficiency of multi-walled carbon nanotubes in adsorbing humic acid from aqueous solutions. Asian J Chem 26:821

Ponnusami V, Vikram S, Srivastava S (2008) Guava (Psidium guajava) leaf powder: novel adsorbent for removal of methylene blue from aqueous solutions. J Hazard Mater 152:276-286

Qi Y, Yang M, Xu W, He S, Men Y (2017) Natural polysaccharidesmodified graphene oxide for adsorption of organic dyes from aqueous solutions. J Colloid Interface Sci 486:84-96

Rahimi S, Poormohammadi A, Salmani B, Ahmadian M, Rezaei M (2016) Comparing the photocatalytic process efficiency using batch and tubular reactors in removal of methylene blue dye and COD from simulated textile wastewater. J Water Reuse Desalin 6:574-582

Ramavandi B, Farjadfard S (2014) Removal of chemical oxygen demand from textile wastewater using a natural coagulant. Korean J Chem Eng 31:81-87

Rao MR, Warrier DU, Gaikwad SR, Shevate PM (2016) Phosphorylation of psyllium seed polysaccharide and its characterization. Int J Biol Macromol 85:317-326

Rodrigo S, Saez C, Cañizares P, Rodrigo M (2018) Reversible electrokinetic adsorption barriers for the removal of organochlorine herbicide from spiked soils. Sci Total Environ 640:629-636

Samadi MT, Zolghadrnasab H, Godini K, Poormohammadi A, Ahmadian M, Shanesaz S (2015) Kinetic and adsorption studies of reactive black 5 removal using multi-walled carbon nanotubes from aqueous solution. Der Pharma Chem 7:267-274

Samarghandi MR, Babaee SA, Ahmadian M, Asgari G, Ghorbani Shahna F, Poormohammadi A (2014) Performance catalytic 
ozonation over the carbosieve in the removal of toluene from waste air stream. J Res Health Sci 14:227-232

Satilmis B, Budd PM (2017) Selective dye adsorption by chemicallymodified and thermally-treated polymers of intrinsic microporosity. J Colloid Interface Sci 492:81-91

Seid-Mohammadi A, Gh A, Sammadi M, Ahmadian M, Poormohammadi A (2014) Removal of humic acid from synthetic water using chitosan as coagulant aid in electrocoagulation process for $\mathrm{Al}$ and Fe electrodes. Res J Chem Environ 18:5

Shen K, Gondal M (2017) Removal of hazardous rhodamine dye from water by adsorption onto exhausted coffee ground. J Saudi Chem Soc 21:S120-S127

Singh B, Chauhan G, Kumar S, Chauhan N (2007) Synthesis, characterization and swelling responses of $\mathrm{pH}$ sensitive psyllium and polyacrylamide based hydrogels for the use in drug delivery (I). Carbohyd Polym 67:190-200

Tang W-W, Zeng G-M, Gong J-L, Liu Y, Wang X-Y, Liu Y-Y, Liu Z-F, Chen L, Zhang X-R, Tu D-Z (2012) Simultaneous adsorption of atrazine and $\mathrm{Cu}$ (II) from wastewater by magnetic multi-walled carbon nanotube. Chem Eng J 211:470-478

Wang M-X, Zhang Q-L, Yao S-J (2015) A novel biosorbent formed of marine-derived Penicillium janthinellum mycelial pellets for removing dyes from dye-containing wastewater. Chem Eng J 259:837-844

Wang W, Huang G, An C, Xin X, Zhang Y, Liu X (2017) Transport behaviors of anionic azo dyes at interface between surfactantmodified flax shives and aqueous solution: synchrotron infrared and adsorption studies. Appl Surf Sci 405:119-128

Wang J, Zhang T, Mei Y, Pan B (2018) Treatment of reverse-osmosis concentrate of printing and dyeing wastewater by electro-oxidation process with controlled oxidation-reduction potential (ORP). Chemosphere 201:621-626

Wawrzkiewicz M, Bartczak P, Jesionowski T (2017) Enhanced removal of hazardous dye form aqueous solutions and real textile wastewater using bifunctional chitin/lignin biosorbent. Int J Biol Macromol 99:754-764

Yagub MT, Sen TK, Afroze S, Ang HM (2014) Dye and its removal from aqueous solution by adsorption: a review. Adv Colloid Interface Sci 209:172-184

Yu J-X, Li B-H, Sun X-M, Jun Y, Chi R-A (2009) Adsorption of methylene blue and rhodamine B on baker's yeast and photocatalytic regeneration of the biosorbent. Biochem Eng J 45:145-151

Zadeh KR, Malakootian M (2017) O-3/UV photo-oxidation for the removal of reactive yellow 3 dye from wastewater. Desalin Water Treat 81:322-326

Zhang D, Yin J, Zhao J, Zhu H, Wang C (2015) Adsorption and removal of tetracycline from water by petroleum coke-derived highly porous activated carbon. J Environ Chem Eng 3:1504-1512

Zuo L, Ai J, Fu H, Chen W, Zheng S, Xu Z, Zhu D (2016) Enhanced removal of sulfonamide antibiotics by $\mathrm{KOH}$-activated anthracite coal: batch and fixed-bed studies. Environ Pollut 211:425-434

Publisher's Note Springer Nature remains neutral with regard to jurisdictional claims in published maps and institutional affiliations. 